\title{
Numerical simulation of microstructure evolution and microsegregation of U-Nb alloy during solidification process
}

\author{
*Bin Su', Zhi-qiang Han', Hong-zhang Deng', Rong Ma', Dong Chen', Jun Wu', and Zhen-hong Wang' \\ 1. Institute of Materials, China Academy of Engineering Physics, Jiangyou 621907, Sichuan, China \\ 2. Key Laboratory for Advanced Materials Processing Technology (Ministry of Education), School of Materials Science and Engineering, \\ Tsinghua University, Beijing 100084, China
}

\begin{abstract}
In this work, a cellular automaton model has been developed to simulate the microstructure evolution of U-Nb alloy during the solidification process. The preferential growth orientation, solute redistribution in both liquid and solid, solid/liquid interface solute conservation, interface curvature and the growth anisotropy were considered in the model. The model was applied to simulate the dendrite growth and $\mathrm{Nb}$ microsegregation behavior of U-5.5Nb alloy during solidification, and the predicted results showed a reasonable agreement with the experimental results. The effects of cooling rates on the solidification microstructure and composition distribution of U-5.5Nb were investigated by using the developed model. The results show that with the increase of the cooling rate, the average grain size decreases and the $\mathrm{Nb}$ microsegregation increases.
\end{abstract}

Key words: U-Nb alloy; microsegregation; microstructure; cellular automaton; numerical simulation

CLC numbers: TP391.99 Document code: A Article ID: 1672-6421(2017)05-412-04

$\mathrm{U}$ -Nb alloy, which exhibits many advantages such as special nuclear properties and high density, is widely used in the national defense and nuclear energy engineering field ${ }^{[1-5]}$. Since the density of two elements varies greatly and diffusion of $\mathrm{Nb}$ in uranium is particularly sluggish, microsegregation forms after solidification ${ }^{[5]}$, and it is difficult to eliminate them in subsequent heat treatment process. Therefore, it is of great significance to study of microstructure evolution and microsegregation behavior during the solidification process.

$\mathrm{U}-\mathrm{Nb}$ alloy is expensive and also radioactive, which limits the experimental research. In recent years, a variety of computer models, such as cellular automaton (CA) ${ }^{[6-10]}$, Monte Carlo ${ }^{[11]}$ and phase field ${ }^{[12-14]}$, have been developed to simulate the microstructure evolution during the solidification process. CA method, as an efficient computational approach for microstructural simulation with a high computational efficiency, has been widely applied to the investigation of dendrite morphologies and microsegregation during metal

\section{*Bin Su}

Male, born in 1985, Ph.D. His research interests mainly focus on multi-scale modeling and simulation of casting processes. Currently, he is paying much more attention to the microstructure simulation of uranium alloy.

E-mail: sub703@126.com

Received: 2017-07-31; Accepted: 2017-08-05 solidification.

In this work, a CA model has been developed to simulate the microstructure evolution of $\mathrm{U}-\mathrm{Nb}$ alloy during solidification process. By using the model, microstructure evolution and $\mathrm{Nb}$ microsegregation behavior of $\mathrm{U}-5.5 \mathrm{Nb}$ alloy during solidification process were obtained, and an experiment was conducted for model validation. Then the model was applied to investigating the solidification microstructure and the composition distribution of $\mathrm{U}-5.5 \mathrm{Nb}$ under different cooling rates.

\section{Model description}

The phase diagram of $\mathrm{U}-\mathrm{Nb}$ alloy is illustrated in Fig.1, and analysis of the solidification path was made with U-6Nb (U-14at.\% Nb) as an example. When $T<T_{\mathrm{L}}$ (liquidus temperature, $\mathrm{K}$ ), the molten metal transforms into $\gamma$ phase until this stage is complete. When the temperature reaches $T_{\mathrm{M}}$ (monotectoid temperature, $\mathrm{K}$ ), the monotectoid transformation, $\gamma_{1} \rightarrow \alpha+\gamma_{2}$, occurs. The dendrite microstructure evolutions of U-Nb alloy were simulated using the CA model. In the present model, a two-dimensional computational domain was discretized into square cells with the cell size $\Delta x$. Each of the cells is possessed of several variables, such as solute content, solid fraction, etc. According to the solid fraction $\left(f_{\mathrm{s}}\right)$, the state of the cells can be identified as solid $\left(f_{\mathrm{S}}=1\right)$, 
liquid $\left(f_{\mathrm{S}}=0\right)$, and interface $\left(0<f_{\mathrm{S}}<1\right)$. In order to simulate the dendrite growth process, the governing equations used to calculate distribution of concentration and temperature, growth kinetics, solid fraction, and capturing rules will be described below.

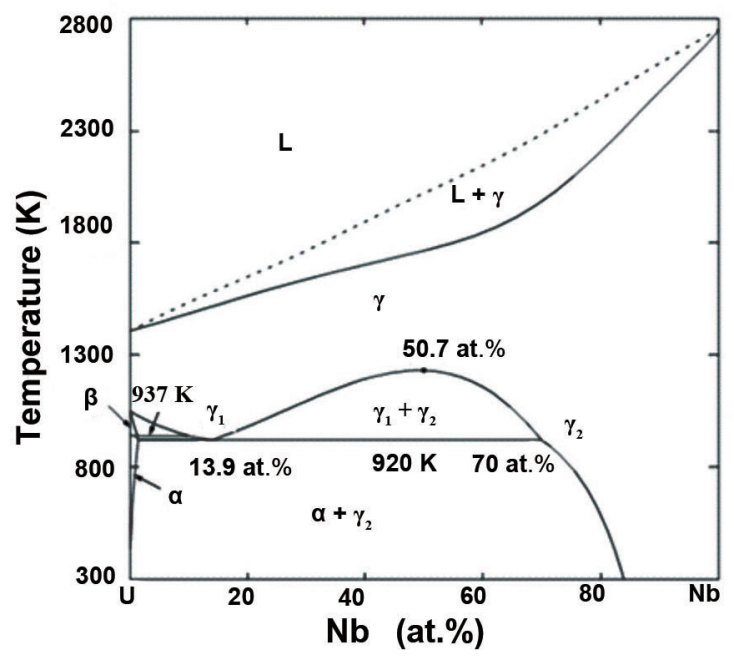

Fig. 1: Phase diagram of U-Nb system ${ }^{[2]}$

\subsection{Nucleation model}

A continuous nucleation model ${ }^{[15]}$ was employed to calculate the nucleus number in the undercooled melts.

$$
\begin{gathered}
n(\Delta T)=\int_{0}^{\Delta T}\left[1-f_{\text {Solid }}\left(\Delta T^{\prime}\right)\right] \frac{\mathrm{d} n}{\mathrm{~d}\left(\Delta T^{\prime}\right)} \mathrm{d}\left(\Delta T^{\prime}\right) \\
\frac{\mathrm{d} n(\Delta T)}{\mathrm{d}\left(\Delta T^{\prime}\right)}=\frac{N_{\max }}{\sqrt{2 \pi} \Delta T_{\sigma}} \exp \left(-\frac{1}{2}\left(\frac{\Delta T^{\prime}-\Delta T_{\mathrm{N}}}{\Delta T_{\sigma}}\right)^{2}\right)
\end{gathered}
$$

where $\Delta T$ is the undercooling $(\mathrm{K}), n(\Delta T)$ is the nucleus density $\left(\mathrm{m}^{-2}\right), N_{\max }$ is the maximum nucleus density $\left(\mathrm{m}^{-2}\right), \Delta T_{\sigma}$ is the standard deviation of the distribution $(\mathrm{K}), \Delta T_{\mathrm{N}}$ is the mean nucleation undercooling $(\mathrm{K}), \Delta T^{\prime}$ is the undercooling integral element $(\mathrm{K})$, and $f_{\text {Solid }}\left(\Delta T^{\prime}\right)$ is the fraction of solid phase.

\subsection{Solute diffusion}

During the solidification process for an alloy, the solute diffusion is solved in the liquid and solid region.

$$
\begin{aligned}
& \frac{\partial C_{\mathrm{L}}}{\partial t}=\nabla \cdot\left(D_{\mathrm{L}} \nabla C_{\mathrm{L}}\right) \\
& \frac{\partial C_{\mathrm{S}}}{\partial t}=\nabla \cdot\left(D_{\mathrm{S}} \nabla C_{\mathrm{S}}\right)
\end{aligned}
$$

where $C$ is the solute composition (wt.\%), $D$ is the solute diffusion coefficient $\left(\mathrm{m}^{2} \cdot \mathrm{s}^{-1}\right)$, and the subscripts $\mathrm{L}$ and $\mathrm{S}$ mean the liquid and solid, respectively, and $t$ is the time (s).

\subsection{Interface growth kinetics}

The relationship between the equilibrium composition and the interface temperature is given by equation (5) and equation (6):

$$
\begin{aligned}
& \mathrm{C}_{\mathrm{L}}{ }^{*}=C_{0}+\frac{T^{*}-T_{\mathrm{L}}+\Delta T_{\mathrm{R}}}{m_{\mathrm{L}}} \\
& C_{\mathrm{S}}{ }^{*}=k_{0} C_{\mathrm{L}}{ }^{*}
\end{aligned}
$$

where $T^{*}$ is the interface temperature $(\mathrm{K}), T_{\mathrm{L}}$ is the liquidus temperature $(\mathrm{K}), C_{\mathrm{L}}{ }^{*}$ and $C_{\mathrm{S}}{ }^{*}$ are the equilibrium liquid and solid composition (wt.\%), respectively, $C_{0}$ is the initial composition (wt.\%), $\Delta T_{\mathrm{R}}$ is the curvature undercooling $(\mathrm{K}), m_{\mathrm{L}}$ is the slope of the liquidus line $\left(\mathrm{K} \cdot \mathrm{wt} . \%^{-1}\right)$, and $k_{0}$ is the solute partition coefficient.

In two-dimensional conditions, considering the GibbsThomson effect, the curvature undercooling of ternary alloys is given by equation $(7)^{[16]}$ :

$$
\Delta T_{\mathrm{R}}=\Gamma\left[1-15 \varepsilon\left(4\left(\psi-\psi_{0}\right)\right] \cdot K\right.
$$

where $\Gamma$ is the Gibbs-Thomson coefficient $(\mathrm{K} \cdot \mathrm{m}), \varepsilon$ is the degree of anisotropy of the interfacial energy, $\psi$ is the inclined angle $\left(^{\circ}\right)$ of the normal to the interface with respect to the coordinate axis, $\psi_{0}$ is the angle $\left(^{\circ}\right)$ between the preferred growth direction and the coordinate axis, and $K$ is the curvature of the interface $\left(\mathrm{m}^{-1}\right)$.

The average curvature for an interface cell is affected by its neighboring cells, and is calculated with the following expression $^{[17]}$ :

$$
K=\left[1-2\left(f_{\mathrm{S}}+\sum_{i=1}^{N} f_{\mathrm{S}}(i)\right) /(N+1)\right] / \Delta x
$$

where $f_{\mathrm{S}}(i)$ and $N$ are the solid fraction and the number of the neighboring cells. In the present model, $N$ equals 8 .

Solute conservation at the $\mathrm{S} / \mathrm{L}$ interface is given by Eq. (9) ${ }^{[16]}$.

$$
v_{\mathrm{n}} C_{\mathrm{L}}^{*}\left(1-k_{0}\right)=-D_{\mathrm{L}}\left(\frac{\partial C_{\mathrm{s}}}{\partial x}+\frac{\partial C_{\mathrm{s}}}{\partial y}\right)+D_{\mathrm{S}}\left(\frac{\partial C_{\mathrm{L}}}{\partial x}+\frac{\partial C_{\mathrm{L}}}{\partial y}\right)
$$

where $v_{\mathrm{n}}$ is the normal velocity of the interface.

After calculating $v_{\mathrm{n}}$, the solid fraction increment of the interface in one time step $\Delta t$ is calculated using the following equations:

$$
\begin{aligned}
& \Delta f_{\mathrm{S}}=\left(\frac{v_{\mathrm{x}} \Delta t}{\Delta x}+\frac{v_{\mathrm{y}} \Delta t}{\Delta y}-\frac{v_{\mathrm{x}} v_{\mathrm{y}} \Delta t^{2}}{\Delta x \Delta y}\right) \\
& f_{\mathrm{S}}^{t_{0}+\Delta t}=f_{\mathrm{S}}^{t_{0}}+\Delta f_{\mathrm{S}}
\end{aligned}
$$

where $v_{\mathrm{x}}$ and $v_{\mathrm{y}}$ are the growth velocities along the $x$ and $y$ axes $\left(\mathrm{m} \cdot \mathrm{s}^{-1}\right), \Delta f_{\mathrm{S}}$ is the increment of solid fraction, $f_{\mathrm{S}}^{\mathrm{t}_{0}}$ and $f_{\mathrm{S}}^{t_{0}+\Delta t}$ are the solid fraction at the current time step and the next time step, respectively. When $f_{\mathrm{S}}$ equals 1 , the interface cell becomes solid and captures the neighboring liquid cells, and the captured cells change its state to interface.

\section{Results and discussion}

\subsection{Solidification microstructure}

Depleted uranium and niobium wire were used for the preparation of $\mathrm{U}-\mathrm{Nb}$ alloys. $\mathrm{U}-5.5 \mathrm{Nb}$ alloy was melted in an arc melting furnace under vacuum up to $10 \mathrm{~Pa}$ at temperature of about $1,520^{\circ} \mathrm{C}$ for $30 \mathrm{~min}$, and then the liquid metal was directly cast into ingots. A thermocouple was positioned at the center of the ingot to measure the temperature variation during the solidification process. Samples for microstructure observation were taken from the center of the ingot. Standard metallographic techniques were adopted for grinding and polishing. 5\% $\mathrm{H}_{3} \mathrm{PO}_{4}$ aqueous solution was applied for electroetching and constant $2 \mathrm{~V}$ DC bias was used for the etching. The microstructure was observed using optical microscope and scanning electron microscope (SEM).

Figure 2 shows the as-cast microstructure of U-5.5Nb taken 
from the center of the ingot. It can be seen that the equiaxed white areas were the primary $\gamma$ phase that were the first to

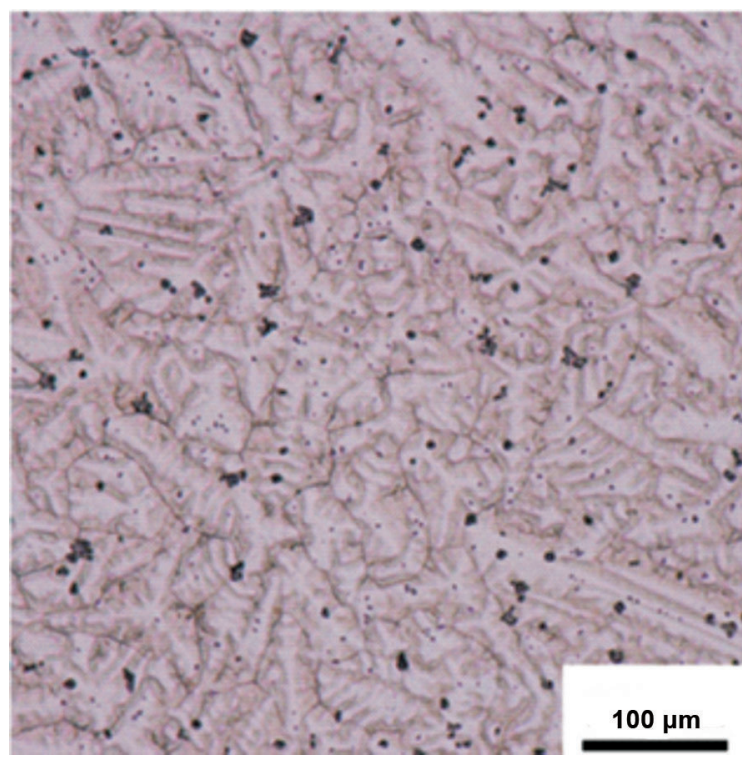

Fig. 2: As-cast microstructure of U-5.5Nb alloy

The simulation was carried out to investigate the dendrite morphology and the solute distribution. A single solid seed with initial composition $k_{0} C_{0}$ and preferential crystallographic orientation of $0^{\circ}$ with respect to the horizontal direction was set at the center of the domain. The constant cooling rate of $1 \mathrm{~K} \cdot \mathrm{s}^{-1}$ was imposed on the domain, and the simulated results are shown in Fig. 3. It can be seen that the dendrite arms can steadily develop along the crystallographic orientation and the dendrite morphology is presented as four-fold symmetry. From Fig. 3, it can be observed that the $\mathrm{Nb}$ concentration decreases near the solidify. The resistance to etching indicates that these firstformed regions have $\mathrm{Nb}$ enrichment ${ }^{[3]}$. There are carbide inclusions observed at the prior $\gamma$ grain boundaries.

\subsection{Numerical simulation}

The computational domain was divided into $600 \times 600$ rectangular cells, and the cell size is $1 \mu \mathrm{m}$. The parameters used in the simulation are shown in Table 1.

Table 1: Properties of U-5.5Nb (wt. \%) binary alloys used in following simulations ${ }^{[1]}$

\begin{tabular}{ll} 
Definition and symbols & Values \\
\hline Liquidus temperature, $T_{\mathrm{L}}(\mathrm{K})$ & 1,633 \\
Liquidus slope, $m_{\mathrm{L}}\left[\mathrm{K} \cdot(\mathrm{wt} . \%)^{-1}\right]$ & 37.3 \\
Liquid diffusion coefficient, $D_{\mathrm{L}}\left(\mathrm{m}^{2} \cdot \mathrm{s}^{-1}\right)$ & $1.05 \times 10^{-9}$ \\
Solid diffusion coefficient, $D_{\mathrm{S}}\left(\mathrm{m}^{2} \cdot \mathrm{s}^{-1}\right)$ & $3.14 \times 10^{-10}$ \\
Partition coefficient, $k_{0}$ & 2.0 \\
Gibbs-Thomson coefficient, $\Gamma(\mathrm{K} \cdot \mathrm{m})$ & $1.9 \times 10^{-7}$
\end{tabular}

dendrite interface as a result of solute redistribution. During the dendrite growth, solute redistribution occurs and the $\mathrm{Nb}$ atom is continuously absorbed into the solid-liquid interface.

The practical solidification process of U-Nb alloy involves equiaxed polycrystalline growth in random crystallographic orientations. The polycrystalline growth of $\mathrm{U}-5.5 \mathrm{Nb}$ alloy during solidification was investigated. The temperature profile for simulation was directly obtained from the measured cooling curve (the average cooling rate is $5 \mathrm{~K} \cdot \mathrm{s}^{-1}$ ), and the temperature was assumed to be uniform in the whole calculation domain. 2D
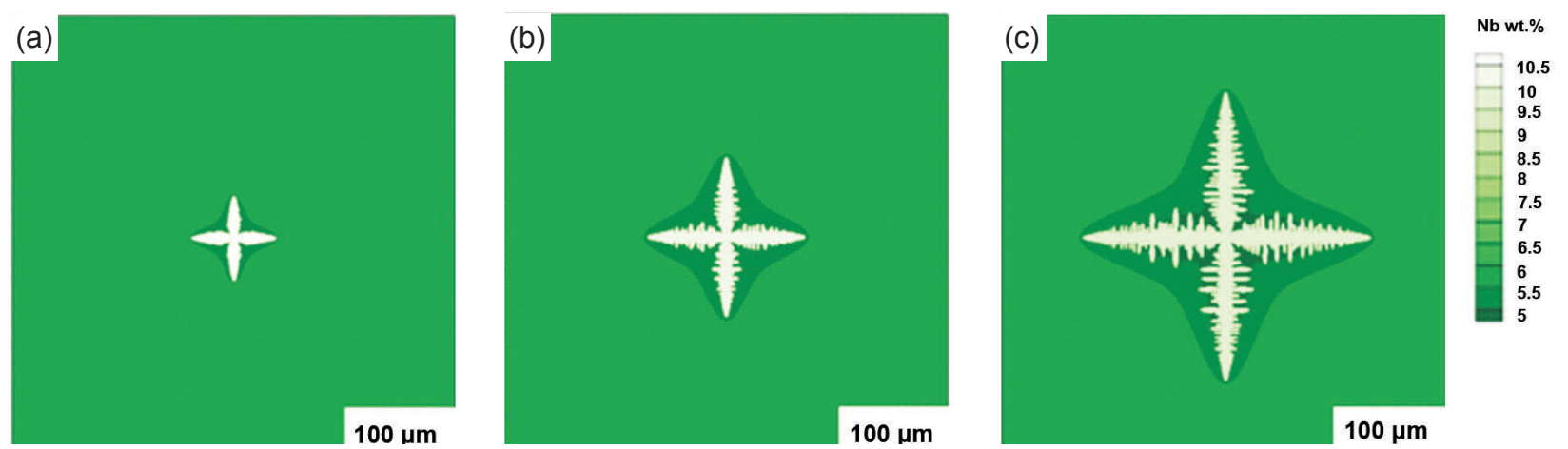

Fig. 3 Dendrite morphology and solute distribution during solidification: simulated microstructure at time of (a) $22.9 \mathrm{~s}$, (b) $31.5 \mathrm{~s}$, (c) $38.1 \mathrm{~s}$
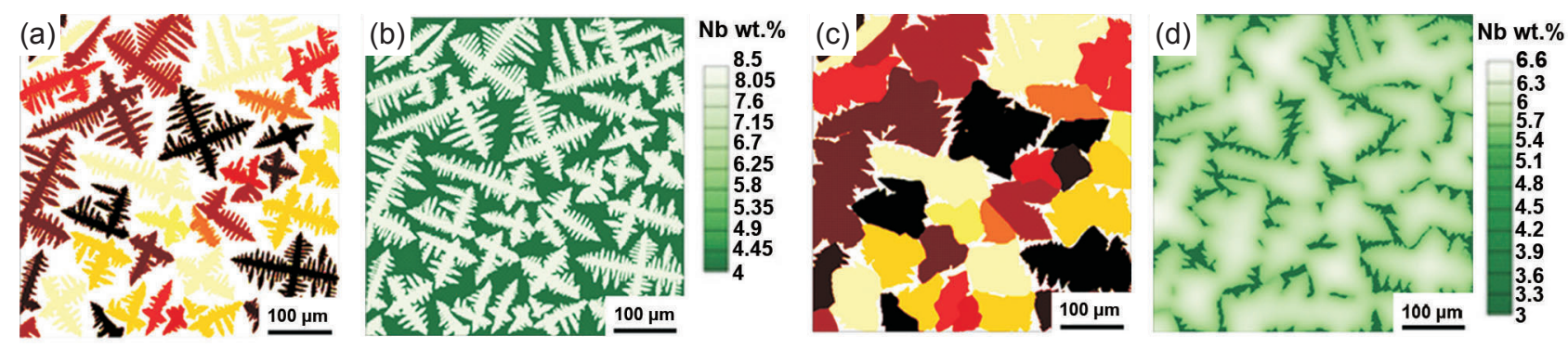

Fig. 4: Simulated dendrite microstructure and corresponding Nb concentration of U-5.5Nb alloy during solidification: (a) microstructure at $13 \mathrm{~s}$, (b) solute distribution at $13 \mathrm{~s}$, (c) microstructure at $22.5 \mathrm{~s}$, (d) solute distribution at $22.5 \mathrm{~s}$ 
simulations were performed in a domain with the size of $0.6 \times 0.6$ $\mathrm{mm}^{2}$. Figure 4 shows the simulated dendrite microstructure and corresponding $\mathrm{Nb}$ concentration of $\mathrm{U}-5.5 \mathrm{Nb}$ alloy during solidification. It can be seen that the dendrites will grow continuously until they meet each other. With the coarsening of dendrite arms, the liquid among interdendritic regions and grain boundaries are separated into discrete liquid droplets in which the solute is poor, which leads to $\mathrm{Nb}$ microsegregation after solidification. Figure 4 (c) and (d) show the final microstructure and corresponding $\mathrm{Nb}$ concentration of $\mathrm{U}-5.5 \mathrm{Nb}$ alloy, respectively. It can be seen that the morphology of the simulated microstructure is quite close to the observed result (Fig. 2).
In order to investigate the influences of different cooling rates on the solidification microstructure of $\mathrm{U}-\mathrm{Nb}$ alloy, the model was used to simulate dendrite microstructure and corresponding $\mathrm{Nb}$ concentration of $\mathrm{U}-5.5 \mathrm{Nb}$ alloy during solidification at the cooling rate of 1,5 and $50 \mathrm{~K} \cdot \mathrm{s}^{-1}$, respectively. From Fig. 4 and Fig. 5, it can be seen that with the increasing cooling rate, the nucleation density increases and the secondary dendrite arm spacing decreases, both of which result in the refinement of the microstructure. The results show that with the increase of the cooling rate, the average grain size decreases and the $\mathrm{Nb}$ microsegregation increases.
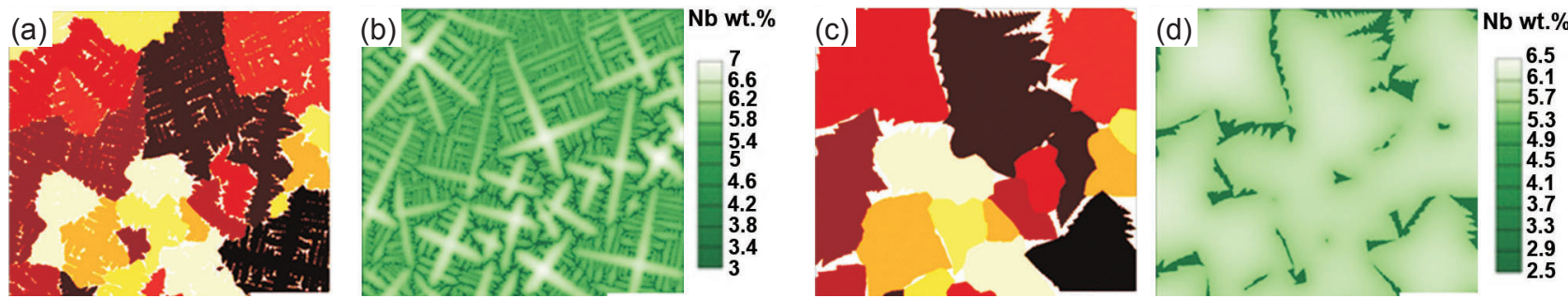

Fig. 5: Simulated final dendrite microstructure and corresponding $\mathrm{Nb}$ concentration of U-5.5Nb alloy during solidification at different cooling rates: (a) microstructure at cooling rate of $50 \mathrm{~K} \cdot \mathrm{s}^{-1}$, (b) solute distribution at cooling rate of $50 \mathrm{~K} \cdot \mathrm{s}^{-1}$, (c) microstructure at cooling rate of $1 \mathrm{~K} \cdot \mathrm{s}^{-1}$, (d) solute distribution at cooling rate of $1 \mathrm{~K} \cdot \mathrm{s}^{-1}$

\section{Conclusion}

A cellular automaton model has been developed to simulate microstructure evolution of U-Nb alloy during the solidification process. The evolution of dendrite morphology and the $\mathrm{Nb}$ distribution of U-5.5 $\mathrm{Nb}$ during solidification were simulated. To validate the model, an ingot was produced and metallographic examination was carried out. It was shown that the simulated result is in good agreement with the experimental result. The effects of cooling rates on the solidification microstructure and composition distribution of $\mathrm{U}-5.5 \mathrm{Nb}$ were investigated by using the developed model. The results show that with the increase of the cooling rate, the average grain size decreases and the $\mathrm{Nb}$ microsegregation increases.

\section{References}

[1] Li Qiang, Ma Yingche, Liu Kui, et al. Modeling of microstructure and microsegregation of $\mathrm{U}-6 \% \mathrm{Nb}$ binary alloy during solidification process. Acta Metallurgica Sinica, 2007, 43 (2): 217-224. (In Chinese)

[2] Liu X J, Li Z S, Wang J, et al. Thermodynamic modeling of the U-Mn and U-Nb systems. Journal of Nuclear Materials, 2008, 380: 99-104.

[3] Kelly A M, Field R D, Thoma D J. Metallographic preparation techniques for U-6wt.\%Nb. Journal of Nuclear Materials, 2012, 429: 118-127.

[4] Ji Hefei, Chen Xianglin, Shi Peng, et al. The effects of microstructure on the hydriding for $500{ }^{\circ} \mathrm{C} / 2 \mathrm{~h}$ aged $\mathrm{U}-13$ at. \% Nb alloy. Journal of Nuclear Materials, 2017, 488: 252-260.

[5] Jackson R J, Kangas C V. Homogenization of uranium-base nibium alloys. RFP-1582.

[6] Li Qiang, Li Dianzhong, Qian Bainian. Modelling of the redistribution of solute concentration in dendrite solidification process. Acta Metallurgica Sinica, 2004, 40 (11): 1215-1220. (In Chinese)
[7] Huang Weidong, Wang Meng. Progress and development trends in the numerical modeling of solidification. Chinese Science Bulletin, 2014, 59 (15): 1709-1718.

[8] Yang Manhong, Guo Zhipeng, Xiong Shoumei. Numerical simulation of dendritic growth of magnesium alloy with convection. The Chinese Journal of Nonferrous Metals, 2015, 25 (4): 835-843. (In Chinese)

[9] Chen Rui, Xu Qingyan, Liu Baicheng. Cellular automaton simulation of three-dimensional dendrite growth in Al-7Si-Mg ternary aluminum alloys. Computational Materials Science, 2015, 105: 90-100.

[10] Zhu Mingfang, Tang Qianyu, Zhang Qingyu, et al. Cellular automaton modeling of micro-structure evolution during alloy solidification. Acta Metallurgica Sinica, 2016, 52 (10): 1297-1310. (In Chinese)

[11] Wang Tongmin, Jin Junze, Zheng Xianshu, Ohnaka Itsuo. A novel simulation method for the prediction of dendritic grain structures in solidification. International Journal of Cast Metals Research, 2002, 231236

[12] Wang Mingyue, Jing Tao, Liu Baicheng. Phase-field simulations of dendrite morphologies and selected evolution of primary $\alpha-M g$ phases during the solidification of Mg-rich Mg-Al-based alloys. Scripta Materialia, 2009, 61 (8): 777-780.

[13] Yin Yajun, Zhou Jianxin, Liao Dunming, et al. Phase-field simulation of dendritic solidification using a full threaded tree with adaptive meshing China Foundry, 2014, 11 (6): 493-497.

[14] Pan Haowei, Han Zhiqiang Liu, Baicheng. Study on dendritic growth in pressurized solidification of Mg-Al Alloy using phase field simulation. Journal of Materials Science \& Technology, 2016, 32 (1): 68-75.

[15] Rappaz M, Gandin C A. Probabilistic modeling of microstructure formation in solidification processes. Acta Materialia, 1993, 41: 345360.

[16] Beltran-Sanchez L, Stefanescu D M. A quantitative dendrite growth model and analysis of stability concepts. Metallurgical and Materials Transactions A, 2004, 35 (8): 2471-2485.

[17] Nastac L. Numerical modeling of solidification morphologies and segregation patterns in cast dendritic alloys. Acta Materialia, 1999, 47 (17): 4253-4262. 